\title{
Guideline for the Development and Management of Music and Performing Arts in Khwaeng Champasak, Lao PDR
}

\author{
Thanyalak Ubonlert ${ }^{1}$, Thinakorn Atapaiboon ${ }^{1} \&$ Chaloey Pumipuntu ${ }^{1}$ \\ ${ }^{1}$ College of Music Mahasarakham University Khamriang Sub-District, Kantarawichai District, Maha Sarakham \\ Province, Thailand \\ Correspondence: Thanyalak Ubonlert, College of Music Mahasarakham University Khamriang Sub-District, \\ Kantarawichai District Maha Sarakham, 44150, Thailand. Email: Thanyaluk.u@gmail.com
}

Received: June 25, $2014 \quad$ Accepted: July 4, $2014 \quad$ Online Published: September 22, 2014
$\begin{aligned} & \text { doi:10.5539/ach.v7n1p126 } \\ & \text { URL: http://dx.doi.org/10.5539/ach.v7n1p126 }\end{aligned}$

\begin{abstract}
In the years after 1975, the governmental system of Lao PDR was transformed into socialism. A main question is how music and performing arts in Khwaeng Champasak of Lao PDR adapt themselves to this change. The purpose of this research is to investigate the history, current situation and the method of developing management of music and performing arts in Khwaeng Champasak. The research method is qualitative research using the integration of documentary study and field study. Research instruments are an observation and an interview. The sample consisted of 40 people who are 5 experts in the field of management, 5 artists, 5 academics, 15 people concerning music and performing arts, and 10 general people. A qualitative research method is used for searching the findings. An research method is used for searching the findings. An observation and an interview are main instruments.
\end{abstract}

The research found that when Lao PDR was ruled by the monarchy, traditional Laos music was patronized by the king but the music in the form of Mor Lam, Mor Khab (folk singer performance), and tribal music was the entertainment for general people. The Lao government used the performances of Lam Som and Lam Sipandon (the two kinds of folk singer performances) as the media to publicize the policy, information, knowledge and to create social harmony.

The study of current situation has revealed that the state sector plays a role in preserving and carrying on the traditional music, tribal music, and various kinds of musical performances by organizing their performances in the important events. General private organizers also employ Mor Lam groups to perform in traditional fairs of communities.

As for the method of developing management of music and performing arts in Champasak, it has revealed that the state sector emphasizes the important of developing both state artists and private artists parallel to the tourism development. Thus, the artists have a good chance to develop themselves in order to please the audience and responded the policy of the government

Keyword: Guidelines, music and performing arts, khwaeng champasak, qualitative research

\section{Introduction}

The science and art of managing organization is necessary for all types and scales of organizations. The organizations performing art performances also need the efficiency of managements since it will enhance art performances succeed perfectly. The process of management involves all sections in each organization so all staff should learn to manage their works efficiently.

Lao People's Democratic Republic and Thailand have maintained a close relationship with each other for long time. Although both countries sometimes were ruled by the different regimes but the relationship did not change. Sine social development of both countries originated from the same mould that is Buddhism so many traditions and rituals are alike. In terms of music and performing arts, there are many differences in details between both countries (Mapecht, 2012)

The lower region of Laos such as the provinces of Savannakhet, Pak Sei, Don Khong, and Champasak have their own cultural identities especially in terms of music and performing arts that called Moe Lam. The art of Mor Lam performance has been transmitted among Thai and Lao people living in the both sides of the Mekong River Basin. Mor Lam or a folk-singer show has be popular among Thai and Lao people up to now. In the past this region was 
under the Lan Xang Kingdom of Laos and afterwards the right side of the Mekong River Basin was under the Siam Kingdom of Thailand, thus Mor Lam performance performing in the left and the right sides of this region are different in some details (Attapaiboon, 2010)

Khwaeng Champasak or Champasak Province of the lower Laos has its own identity concerning music and performing arts. In the past, music and performing arts was divided into two types: the first was music and performing arts for performing in the royal presence and the second was for performing in public. The first one sometimes called The Traditional Lao Music and Performing Arts and the second one called The Lao Folk Music and Performing Arts. As for the second one, it is classified into many types such as Lam Som, Lam Si Pan Don, the two types of music and performing arts are still popular with Lao people at the present. Both Lam Som and Lam Si Pan Don are classified as a type of musical (Phikunsri, 2008)

The migration of Lao people to other countries has continued since 1975. Many of them are performers and musicians. As for performers and musicians still living in their country must adapt themselves to the policy of republic of the government. The musicals, musical performances, plays and other types of entertainment must respond to the requirements of the public or the special requirements of government. The regime changed from monarchy to republic so all of the elements of musical performances and plays also need some changes, the efficient management plays an important role for these performances. This research may suggest the appropriate ways for performing music and performing arts in Khwaeng Champasak, Lao PDR.

\section{Purposes and Objectives}

The purposes of this research were as the following:

1. To investigate the history of the management of music and performing arts in Khwaeng Champasak, Lao PDR.

2. To investigate current situation and the method of developing management of music and performing arts in Khwaeng Champasak, Lao PDR.

\section{Materials and Methods}

A methodology of qualitative research was used for this investigation. The elements of the research were as follows:

1. Research contents:

1.1 the history or the management of music and performing arts in Khwaeng Champasak, Lao PDR.

1.2 current situation and the method of developing management of music and performing arts in Khwaeng Champasak, Lao PDR

2. Research area:

Khwaeng Champasak, Lao PDR

3. Research sample:

3.115 experts in the field of music and performing arts.

3.210 performers

3.35 managers or the leaders of musical and performing groups.

3.410 general people consisted of organizers, the audience, and tourists.

4. Research instruments:

4.1 observation

4.2 a survey

4.3 an interview

\section{Research period}

One year.

The first stage is a documentary investigation, the researchers searched dissertations and documents concerned for understanding and answering all research purposes. These dissertations and documents were gathered and categorized as a base of knowledge for this research. An observation form, a survey form and an interview form were based on in formation from this base. 
The second stage is a creation of research instruments, an observation form, a survey form and an interview form were created in this stage. All forms were examined by the experts and then these forms were improved according to the advice of the experts.

The third stage is a field study, after all appointments had been already made, the researchers began to conduct a field study according to the dates of appointments in Khwaeng Champasak of Lao PDR. This field study period was about 12 months. The data were collected for responding all research purposes.

The fourth stage is a data correction and research synthesis, the data were examined and corrected by using a triangulation technique. This technique used for examining the relation between situations and dates, situations and places, and situations and persons. When everything was corrected, the researchers began to make a research report until it had been finished.

The fifth stage is a presentation, the researchers presented a research report in the presence of research committee. A descriptive analysis was presented through multimedia. Afterwards, the research report was published by the university press.

\section{Results and Discussion}

In terms of the history of the management of music and performing arts in Khwaeng Champasak of Lao PDR, it has revealed that in the past traditional Lao music and performing arts were supported by the king, all people under the patronage of the king were the people of honor and had adequate property so everything they presented, they did it for the king and royalties. Thus, the leader and manager of each performing art group tended to manage everything according to requirements of the King and the royalties. All of the leaders and managers managed all elements of their groups by themselves, for example; groups' budgets, staff's duties, staff's salaries, groups' materials and machines, and performing elements. Furthermore, songwriters and play writers wrote their works in order to extol the virtue of the king and most works concerning chronicles or historical records. Lao PDR changed its regime from monarchy to republic on December 2, 1975 and proclaimed to used the policy or NEM (New Economic Mechanism) throughout the country in 1986 so the leaders of musical anc performing groups performed and managed themselves under the policy of the government. A culture of performance has responded to the public and the government since then. The method of management and the pattern of performance like this also diffuses to the musical and performing groups living in northeast Thailand. This is consistent with Fritz Graebner (1911), he said that culture traits developed in just a few key areas of the world, these culture traits of various civilizations then diffused out to other cultures in geographically concentric circles. It is also consistent with Supattra Supap (1989), she pointed out that cultural diffusion could diffuse from a group originating it to other groups both internal and external society.

As for music and performing arts for entertaining general people, the leader or manager of each group tended to adjust everything according to general people's requirements. Songs , performing patterns, and stories concerned were adapted in order to be congruent with the way of life of the people. The famous performing arts called Lam So Phan Don and Lam Som were popular with Lao people, especially the Lao people living in Khwaeng Champasak. Both types of performing arts were folk musicals which created an interactive atmosphere between performers and the audience. The two kinds of performing arts are cultural heritage handed down to Champasak people and some of them can sing some verses to exchange actively with performers singing verses on the stage. The interaction between the audience and the performers enhances funny atmosphere for each performance. This is consistent with an ideal of Somsak Srisantisuk (2001) which suggested that when social context was changed, some parts of culture also needed to change in order to maintain the whole of society.

Current situations of music and performing arts are affected by the flow of globalization. All of musical and dramatic performances are responded to the republic policy of the government and the requirements of organizers. All of artists and performers both work for state and private organizations, they still maintain these types of performing arts by transmitting them to the next generation. At present, artists, performers, and persons concerned can lead their life by these occupations happily because cultural tourism in Laos is being popular with foreign tourists. The foreign tourists wants to see traditional Lao musical or performing arts such as Mo Lam (Lao folksinger band), Dontri Lao Doem (traditional Lao orchestra) and other Lao performances, especially the tourists who aim to study traditional Lao performing arts. This is consistent with the research result of Tinnakorn Attapaiboon (2011), it has revealed that music and performing arts tend to adapted their performing patterns to the tourism policy of the government and the flow of globalization, including the high competition among travel agents both internal and external the country. The competition among travel agents in Laos and outside of Laos is still intense so musical and performing groups in Khwaeng Champasak must adapt themselves to this change in order to be chain units of a tourism network of Laos. 
As for the method of developing management of music and performing arts in Khwaeng Champasak, both state and private sectors cooperate to develop the management of music and performing arts systematically. In terms of personnel, a new generation interested in these fields are trained for the future performers, music and performing arts is one of all subjects on the national curriculum. In terms of budget management, each performing group has its own system of budget management which covers all expenses and each item of the expenses can transparently examine, the time table of performances is systematically set, and the government often organizes activities of tourism promotion by supporting some budget for performing groups which participate in the activities. In terms of machine and material management, each performing group tends to hire a truck service when it wants to carry performers, stage sets, light and sound equipment, and others concerned instead of buying it at a high cost. Most of Lao performing groups still use a close relationship in a form of kith and kin for making interna solidarity; for example when someone want to receive some financial help, he or she can ask the manager to support him or her and all members participate in solving this problem. Moreover, a strategy of put the right man on the right job is used for developing the management of performing groups. This is consistent with Thirarat Lilalertsurakun (2011), she has indicated that each Isan folk singer band adapted itself to social change and a flow of globalization by improving its management in order tom maintain the organization for a long time among many changes, this improving covers man, material, machine, and money.

\section{Conclusion}

The organizations concerning art and cultural affairs can adapt the results of this research to their affairs. Guidelines for the development and management of music and performing arts in Khwaeng Champasak, Lao PDR may be a model for improving organizations concerned in other countries. Certainly, cultural and social context of each country is different but some useful tips from this research may benefit persons or organizations that carry on a cultural affair.

\section{References}

Attapaiboon, T. (2011). The Management of Music and Performing Arts of the Tai Lue Ethnic Group in Yunnan Province. Doctoral Thesis. Maha Sarakham : MahasarakhamUniversity.

Attapaiboon, S. (2010). Singing Styles of the Mekong River Basin: Ubon Ratchathani-Champasak. Doctoral Thesis. Maha Sarakham : Mahasarakham University.

Graebner, F, (1911). Methode der Ethnologie. Heidelberg : Carl Winter's Universitats Buchandlung.

Lilalertkun, T. (2011). Developing the Types of Management of Isan Folk Singer Band to Commercial Purpose. Doctoral Thesis. Maha Sarakham : Mahasarakham University.

Mapecht, C. (2012). Conserving, Perpetuating and Developing Thai-Lao Singing Styles Along Both Sides of the Mekong River for Creating a Cultural Value. Doctoral Thesis. Maha Sarakham: Mahasarakham University.

Phikunsri, C. (2008). Traditional Lao Music. Khon Kaen : Center for Research on Purality in the Mekong Region. Khon Kaen : Khon Kaen University.

Srisantisuk, S. (2001). A Study of Society and Culture: Concept, Methodology, and Theory. Khon Kaen L Amarin Coppy.

Supap, S. (1989). Thai Society and Culture (2nd ed.). Bangkok : Thai Wattana Panich.

\section{Copyrights}

Copyright for this article is retained by the author(s), with first publication rights granted to the journal.

This is an open-access article distributed under the terms and conditions of the Creative Commons Attribution license (http://creativecommons.org/licenses/by/3.0/). 